\title{
CUBA EN MOVIMIENTO: DERRUMBE DEL SOCIALISMO, UNA MIRADA DE PRIMER ORDEN
}

\author{
CUBA IN MOVEMENT: COLLAPSE OF SOCIALISM, \\ A FIRST ORDER LOOK \\ Francisco Alberto Pérez Piñón* \\ GUILLERMO HERNÁNDEZ OROZCO** \\ Jesús Adolfo TRuJillo HOLguín***
}

Recibido: 20 de septiembre de 2017 - Aceptado: 20 de enero de 2018 -

Publicado el 31 de diciembre de 2018

DOI: $10.24142 /$ raju.v13n27a2

\section{Resumen}

El artículo hace referencia a los cambios que se presentan en la República Socialista de Cuba y que la están direccionando a la economía del mercado, como sucedió con la Unión de Repúblicas Socialistas Soviéticas (URSS). La narrativa parte de las interpretaciones de las entrevistas, realizadas de manera aleatoria y casual, efectuadas durante el $1^{\circ}$ al 18 de abril del 2017, en donde se focalizan las medidas

* Doctor en Ciencias Pedagógicas, Instituto Superior de Pedagogía "Enrique E. Varona" (Cuba). Labora en la Facultad de Filosofía y Letras de la Universidad Autónoma de Chihuahua (México). Correo electrónico: aperezp@uach.mx

** Doctor en Ciencias de la Educación, Instituto Superior Pedagógico "Enrique J. Verona" (Cuba). Labora en la Facultad de Artes de la Universidad Autónoma de Chihuahua Correo electrónico: ghernand@uach.mx

*** Doctor en Educación, Universidad Autónoma de Chihuahua (México).. Labora en la Facultad de Filosofía y Letras de la Universidad Autónoma de Chihuahua (México). Correo electrónico: jatrujillo@uach.mx 
generadas ante la pérdida de la esperanza en el modelo socialista, instaurado desde el año 1959, con el triunfo de la Revolución cubana.

Palabras clave: socialismo, capitalismo, economía de mercado, fin de la esperanza.

\section{Abstract}

The article makes reference to the changes that appear in the Socialist Republic of Cuba and that are directing it to the market's economy, as happened with the Union of Soviet Socialist Republics (USSR). The narrative starts from the interpretations of the interviews, carried out in a random and casual way, carried out during the 1st to the 18th of April 2017, where the measures generated are focused on the loss of hope in the socialist model, established since 1959, with the triumph of the Cuban Revolution.

Keywords: Socialism, Capitalism, Market Economy, Loss of Hope. 


\section{INTRODUCCIÓN}

Corría el año 1967, 9 de octubre, cuando se dio la cobertura de los medios de comunicación, principalmente la radio, anunciando el fusilamiento de Ernesto "Ché" Guevara por el sargento boliviano Mario Terán (RuízHealy, 2015); noticias que aun, en aquellos años de niñez, parecía descabellada. La muerte de un personaje, de un guerrillero, contaba mi maestro de cuarto año de primaria, quien mucho admiraba a los protagonistas que por medio de las armas habían realizado la revolución en Cuba, ha implementado un nuevo modo de producción con perspectiva socialista, gracias a la visión del bigotón Castro (para referirse a Fidel Castro Ruz). Estas ideas vienen a mi mente, como las primeras impresiones y deseos de conocer esa histórica isla, lo que ocurrió en 1990, precisamente un año después de la caída del Muro de Berlín y el repliegue de los países socialistas agrupados en la Unión de Repúblicas Socialistas Soviéticas (URSS) hacia las economías de mercado; una vuelta completa hacia el capitalismo (Pérez, 2013).

Lo que motiva al presente artículo es dar a conocer los cambios percibidos en 1990, fecha en que se realizaron los primeros viajes con fines estudiantiles, y los de 2017, cuando se regresó a la isla para construir la presente narrativa; estos últimos son el resultado de las interpretaciones que surgieron a partir de las observaciones de primer y de segundo orden, así como de los testimonios de profesores universitarios, trabajadores de hoteles y restaurantes, conductores de autos de alquiler (llamados almendrones) y encuentros casuales en la calle.

Lo que subyace, a manera de enfoque teórico, en el presente trabajo, son las distintas subjetividades recuperadas por medio de las entrevistas no estructuradas y, en ocasiones, realizadas a profundidad, cuando la interacción daba para ello. De esta manera, se recopiló la visión existente en relación con los acontecimientos que están cambiando en Cuba y que algunos ven como necesarios, mientras que otros los asumen como un verdadero retroceso, resultado de las intervenciones del imperialismo que no pierde de vista hacer negocios en la isla.

Las entrevistas que se narran en el escrito fueron realizadas en la visita a La Habana, República Socialista de Cuba, entre el $1^{\circ}$ al 18 de abril del 2017, y representan el esfuerzo intelectual por dar a conocer los cambios observados, sin la pretensión de ser apodícticos pero sí movidos por las visiones de las personas que han conformado una historia de lucha, y que los hace estoicos ante las carencias y vicisitudes sufridas como parte del bloqueo, 
por cincuenta y siete años, y ante un reparto de la producción de manera socialista; que ya no podemos decir reparto de la riqueza sino un reparto, distribución y consumo de la pobreza, porque es lo único que está palpable, sin necesidad de demostrarlo con técnicas medibles o con ser un estadístico reconocido. Las entrevistas fueron personales, y se enmarcan entre comillas cuando hacen alusión al escenario verbal mencionado por el entrevistado.

\section{INICIO DE LA NARRATIVA}

Cuba es un lugar en donde el valor de un bolígrafo se mide así: "pero para que quieres otro si ese que tienes en la mano aún tiene tinta y puedes escribir cantidad". Esas fueron las palabras de la dependienta cuando se acudió a la librería Alma Matter, a un costado de la Universidad de La Habana, a comprar una pluma, previendo que se terminaría, lo que impediría escribir las notas que originaron estos relatos.

El comentario de la dependienta permite rememorar la cultura del ahorro ante las fuertes carencias que vive la población cubana; esto se relaciona con los comentarios de las personas antes de viajar a Cuba, que decían que había que llevar chocolates, pantalones de mezclilla, jabón y papel para regalar, y con ello podías conseguir lo que desearas, desde lo sexual hasta lo inimaginable. Aprovecho para decir que no es veraz, pero sí es cierto que lo que abre las puertas en Cuba son los dólares americanos, en un principio, y hoy en día los dólares convertibles a cubanos, que reciben el nombre de CUC (Peso Cubano Convertible).

No es de extrañar que a la carencia de artículos de primera necesidad, como se observa en las tiendas o supermercados, se sumen los desperfectos de los aparatos, por tanto uso, como es el caso de los elevadores en los hoteles, las tuberías de agua oxidadas o simplemente la falta de agua, lo que obliga a subir las grandes escalinatas o a no bañarse cuando se desea, pero eso sí, al hacer el reporte, las respuestas, siempre amables, son: "el elevador está quebrao, ya pronto lo arreglan", "se terminó el agua, ya viene el abastecimiento"; la voz amable pero terminante que no acepta más quejas, como ocurre en los países capitalistas, donde los reclamos son interminables y casi siempre resueltos; para eso se paga. 


\section{LAS WIFI LLEGAN A CUBA}

Algo novedoso, y que está en boca de todos los cubanos, es la innovación tecnológica, la conexión vía internet a través de las redes inalámbricas (wifi) públicas, principalmente en áreas cercanas a los hoteles, en donde se pueden observar varias personas sentadas en las aceras y en las bancas de los parques; incluso, algunos llevan su propio asiento para poder acceder a la señal que, por supuesto, es lentísima y se desconecta continuamente. Para acceder al servicio es necesario comprar una tarjeta que permita la conexión, que tiene un costo de siete CuC y dura cinco horas; también están en venta tarjetas para conexión de dos horas con un valor de tres CUC, las cuales se compran en la Empresa de Telecomunicaciones de Cuba (ETECSA), que se encuentra repartida por la ciudad en pequeños establecimientos, y no muchos, lo que hace necesario invertir al menos dos o tres horas para realizar su compra, por las largas filas; no siempre tienen tarjetas en existencia, por lo que allí mismo, en la fila, se corre la voz de donde se están vendiendo y la gente se traslada a hacer nuevamente la fila.

No dejamos de lado que ante la alta demanda para la compra de tarjetas también se empieza a dar una comercialización por parte de personas que las acaparan y las ofrecen al público, con plusvalor, por supuesto; regularmente, tarjetas con duración de dos horas a un costo de cinco CuC: "pero yo necesito una tarjeta de cinco horas. Y cuál es el problema, compra dos de dos horas, o tres de dos horas y ya no tienes que hacer fila y perder tiempo; además, se dice que ya no habrá tarjetas hasta mañana"; lo que origina que, a veces, y por la urgencia, se compre a personas que se dedican a la reventa y, adicionalmente, hay que decirlo, evitar el trato poco amable de los dependientes, porque: "creo que nos falta más preparación para atender el turismo, no estamos acostumbrados, no sabemos cómo atender el público; si te fijas, las filas que se hacen fuera de los establecimientos, cuál es la razón por la que no están dentro, muy simple, si alguien lleva algo sin pagar el dependiente o encargado tiene que pagarlo y te imaginas con su sueldo mensual de 27 CUC cómo le hace. Podrás decirme, pero mira cuántos guardias hay en la tienda vigilando a la gente; sí, pero también ellos, ante tanta gente y confusión, aprovechan y se llevan algo, y pobre dependiente a pagar con su salario".

Otra forma de obtener el acceso a la wifi es la que ofrecen los empleados de los hoteles que conocen la contraseña y, de manera discreta, la ofrecen; "no consiguió tarjeta; si gusta, le puedo proporcionar la contraseña del hotel y esta le dura los días que esté con nosotros". 
Estos son algunos de los cambios que se están generando en Cuba, cuando en los inicios de la revolución no se podía hacer el mínimo negocio o intercambio: "un ejemplo, cuál te gusta, el vendedor de granizado"; ni eso, porque se pensaba que podría ser la génesis de la desigualdad entre las personas; "la venta o intercambio de una calabaza, porque también se tiene deseo y aspiraciones de algo diferente a lo de la 'libreta' de abastecimiento que proporciona el Estado, que hoy en día es cada vez más raquítica. Eso te podía llevar a la cárcel”.

\section{LOS CUENTAPROPISTAS O COMERCIO PRIVADO}

Lo que parecía increíble está llegando, el comercio privado ya bien establecido y que paga impuestos al Estado. Antes, de manera clandestina, se le ofrecía a los turistas en la calle los tradicionales puros, "quiere tabaco, quiere tabaco", de las marcas más prestigiosas, y todos decían que procedían de la fábrica Partagás, la tradicional casa fundada en 1845 que elaboraba puros; hasta te invitaban a conocerla: "está atrás del Capitolio, puedes ir y ver para que te enteres del precio que te estoy dando". Al llegar al lugar el guardia de seguridad ofrecía el mismo producto. También era común la oferta de las famosas pastillas de policosanol ( $\mathrm{PPG}$ ), que sirven para tener un mejor rendimiento sexual y para bajar el colesterol, y que resultan más baratas en la calle que en las farmacias. Había una gran cantidad de personas que te invitaban a comer a un "paladar", con el fin de que les dieran un poco de aceite a cambio de llevar a los clientes, ya que este insumo es de gran valor en la isla y no está en la libreta de abastecimiento. Te ofrecían llevarte con chicas (jineteras) a sus casas, porque era imposible que los cubanos entraran a los hoteles, "a los hoteles no entramos porque no está permitido, para proteger al turismo; no vaya a ser que sufran un atentado o les roben y eso en Cuba es muy delicado". Si se deseaba comer langosta buena, fresca y muy abundante, por una módica cantidad, podía hacerse en casas particulares que la preparaban de manera clandestina; solo había que arriesgarse y de paso conocer esas casas y enterarse de las condiciones precarias de la reducción de espacios, la convivencia de varias familias, negros, mulatos, blancos, los techos agujerados, sin pintura y las paredes semidestruidas, o las altas escaleras de madera crujiente, por lo viejas y sin mantenimiento; también, ente otras cosas, te ofrecían un carro particular que podía llevarte a donde te dirigieras, más barato que los carros del Estado; todo de manera clandestina, ya que si los custodios (policías) se daban cuenta entonces el conductor sufría 
las consecuencias, al turista no le ocurría nada, simplemente se bajaba y continuaba su visita en La Habana.

Lo que antes era clandestino ha cambiado, y se percibe mayor tolerancia para los intercambios o la venta de artículos diversos, que se ofrecen en espacios destinados a ello, solo hay que pagar impuestos; pero aquel vendedor de granizado tiene derecho a hacer su lucha, los vendedores de maní, de vino y miel trabajan de forma normal, ya no se cuidan de los custodios. Ahora se observan negocios de artesanías, ropa, suvenires y alimentos, en tiendas que no son ya propiedad del Estado; por esta razón, los precios de los artículos están dados con base en la demanda, lo que afecta fuertemente a los cubanos. Pongamos un ejemplo, un maestro de universidad, de tiempo completo, tiene un salario complementario a la cartilla de abastecimiento de 27 CuC mensuales, en el 2017, lo que antes utilizaba en los mercados agropecuarios cubanos del Estado, que conservaban precios estandarizados, hasta cierto punto accesibles; ahora, se observa que los particulares están ofreciendo productos o artículos con precios libres y dispares a los del mercado, lo que genera un franco encarecimiento de los insumos de primera necesidad. Qué sucederá cuando el Estado cubano deje de subsidiar los artículos básicos de la alimentación no duraderos, porque de los bienes de consumo duradero el Estado difícilmente se hace cargo; "no es una economía de irracionales, porque tenemos mercados nacionales donde los precios son accesibles, tenemos la cartilla de abastecimiento, además el Estado te permite que si tienes parientes en Miami ellos te pueden enviar hasta cien dólares por mes, en Cuba todos tenemos techo, alimentación y vestido". El problema es que la libreta de abastecimiento es cada vez más raquítica, "nosotros no la usamos, o lo que se recoge lo regalamos a otros que sí lo necesitan, o a veces nos reunimos toda la familia y la hacemos en una comida". La válvula de escape de un socialismo que se ha visto socavado desde 1960, cuando el presidente Eisenhower (Yepe, 2013) instituyó el embargo económico y comercial a Cuba, con el fin de restarle fuerza a Fidel Castro, quien tenía el apoyo del pueblo cubano; era una manera de vencer el incipiente régimen socialista, que además era considerado una amenaza al alinearse Cuba como uno de los países satélites de la entonces URSS.

\section{NIKITA MARIQUITA, LO QUE SE DA NO SE QUITA}

"Las dificultades económicas del 'periodo especial' han obligado al gobierno a permitir actividades privadas, la tenencia de dólares y otras cos- 
tumbres antes impensables. Con esas medidas se han introducido, todavía en bajo grado, la desigualdad y la corrupción" como lo expresa Collazo (2001, p. 137) al referirse a los inicios de la apertura librecambista, que hoy en día crece cada vez más.

En definitiva, este periodo especial, en tiempos de paz, fue originado por las políticas que trajeron aparejadas el repliegue de los países socialistas afiliados a la URSS, a una nueva forma de dirección de la sociedad que, a raíz de las políticas conocidas como la Perestroika y la Glásnot, fueron acercándolos al bloque de los países occidentales. Un pensamiento nuevo, más humanista, y reformas favorables a la liberalización de la economía, impulsadas por Mijaíl Gorbachov al subir al poder en 1985 (Dacal y Brown, 2005), originarán la desintegración de URSS al propugnar la autonomía y libertad de los países y el derecho a elegir su propio desarrollo; esto impactó a Cuba, ya que en definitiva, la relación que tenía con URSS era de apoyo, al compartir la ideología socialista, y eso posicionaba a la isla en los países del bloque socialista; además de los intercambios comerciales establecidos al ser parte de los países del Consejo de Ayuda Mutua Económica (CAME), creado desde 1949 como resultado y en respuesta a lo que se denominó la guerra fría, y disuelto ante la caída de los países del bloque socialista. Sin embargo, ya Fidel había recibido anteriormente muestras de que URSS, como su aliado, lo había aprovechado y utilizado, como ocurrió en el episodio bélico considerado como la guerra nuclear por la crisis de los misiles en el año 1962, cuando la aviación de los Estados Unidos se enteró de la construcción de bases para los misiles y tropas rusas en las costas de Cuba, lo que ocasionó un gran despliegue naval y militar que estuvo a punto de desatar una hecatombe mundial, que fue superada gracias a las negociaciones secretas entre los poderosos hombres de URSS y Estados Unidos, Nikita Krushev y John F. Kennedy, en la que se acordó retirar la base de los misiles rusos de Cuba, así como Estados Unidos se comprometió a retirar de Turquía las bases de los misiles Júpiter que tenía en sus costas, además de no invadir la isla. De todas estas negociaciones estuvo excluido el líder cubano Fidel Castro ("La crisis de los misiles en Cuba", s. f.).

La frase con la que se inicia esta sección, "Nikita mariquita, lo que se da no se quita", hace alusión a la salida de las tropas rusas y, con ello, a las inversiones de los rusos en la isla, lo que generaba un bienestar económico a la población que sentía y sufría ya los embates del embargo, que se fue convirtiendo en bloqueo con el fin de exterminar el régimen de Castro, que tenía como objetivo crear el descontento social y que este ocasionara su derrum- 
be; sin embargo, al parecer se han olvidado del estoicismo de la población y el orgullo que, aunque cada vez menos, acompaña a los cubanos, porque de los que hicieron la revolución son ya muy pocos los que sobreviven; eso se evidencia en los comentarios de los jóvenes, que dicen: "no me tocó la revolución, yo la conozco por mis abuelos, cuando dicen que esto estaba peor, pero yo qué culpa tengo, en cuanto pueda me salgo de la isla".

En voz de los entrevistados cubanos, y en relación con el incidente de la Crisis de los misiles, se dice: "allí Fidel se dio cuenta de que estaba solo, lo vieron como cualquier guajiro", al dejarlo fuera de las negociaciones que le dieron solución a la conflagración bélica inminente; "en realidad Cuba no tenía misiles, apenas estaban poniendo las bases y los que estaban instalados no tenían la cabeza nuclear, esta la cuidaban los técnicos, y si la guerra se hubiera venido no iban a poder armar ni los misiles".

El ajuste más fuerte en el periodo especial, en tiempos de paz para los cubanos, se originó por el cambio de dirección y las medidas asumidas por la extinta en 1990; la libreta de abastecimiento se redujo, lo que ocasionó que se quedaran solos; esto explica la gran emigración de la población, "gusanos, esos son gusanos", a otros países, principalmente a Estados Unidos, y que al terminarse las reservas del Estado originó la Crisis de los balseros: "cifras oficiales cubanas indican que cerca de 660.000 cubanos emigraron desde la llamada 'Crisis de los Balseros' en 1994 hasta el 2015" (Gámez, 2016, s. p.); en esos tiempos "yo trabajaba en Ciudad Libertad y mi esposa en Boyeros, teníamos una bicicleta pero yo nunca aprendía a arrearla, así que yo pedía botella y donde me dejaban allí seguía caminando, teníamos que trabajar y lo hacíamos con gusto".

Estos sufrimientos del pueblo cubano continúan, aunque se aminoraron con la llegada, en 1998, de Hugo Chávez a la presidencia de Venezuela, con quien Cuba estableció relaciones de apoyo e intercambios comerciales, "ya llegó el buque de Venezuela, eso quiere decir que tendremos gasolina para las guaguas" y, posteriormente, con el presidente electo de Bolivia, en el 2005, Evo Morales. Aunque también es necesario mencionar que países como México no rompieron relaciones con Cuba, pero siempre siendo cuidadosos de la ira del coloso del norte; para ello, es suficiente la muestra del "comes y te vas", la frase del ridículo histórico del presidente Vicente Fox Quesada, quien no deseaba quedar mal con el presidente de Estados Unidos, Jorge W. Bush, en el año 2012, cuando se iba a celebrar la Cumbre de las Américas en la ciudad de Monterrey, México, y a la que Fidel Castro, a última hora, avisa que acudirá, por lo que le pidió que viniera como amigo, 
pero que se fuera antes de que Bush llegara: "comes y te vas" ("“Comes y te vas', la anécdota entre Vicente Fox con Fidel Castro", 2016).

Si Rusia, el ícono de la revolución socialista y quien puso en marcha el socialismo real, había dado marcha atrás con el centralismo democrático al liberar a sus países satélites y dejarlos en franca autodeterminación política y económica, relacionada con el pensamiento y la economía capitalista, como ocurría en los países occidentales, qué sucedió con Cuba, que sufría constantemente el embargo comercial de Estados Unidos desde 1960, con las declaraciones de Eisenhower, y que se vio agudizado al enfrentar la invasión a la Bahía de Cochinos en 1961, auspiciada por la Compañía de Inteligencia Americana (CIA), además de la Crisis de los misiles en 1962, la caída del Muro de Berlín en 1989 y el cambio de los países socialistas hacia la economía de mercado ("El Muro de Berlín. Esta es la historia del símbolo de la Guerra Fría a 27 años de su caída", 2016), la desintegración de la URSS y por lo tanto el CAME, la visita del papa Juan Pablo II en 1998 y la frase memorable: "Que Cuba se abra el mundo y el mundo se abra a Cuba" para que los sufrimientos de la población cubana se vayan aminorando. Lo que pasó fue que Cuba, poco a poco, se quedó sola: "no sé qué pasó, pero lo que sí está muy claro es que en estos cincuenta y siete años perdimos una generación de cubanos, esperábamos mejorar con Obama, pero ahora con Trump qué va a pasar", en alusión a los miles de cubanos exiliados, a las familias separadas y a la miseria del pueblo cubano que se está quedando sin jóvenes ya que emigran en la búsqueda de oportunidades.

Qué va a suceder. La misma fuente de Vázquez Montalbán sostiene: "se espera que pase algo, pero después de Castro [...] todo lo hacen depender de la desaparición biológica de Castro" (Collazo, 2001, p. 135); esto ya ocurrió en 2016 cuando murió Fidel Castro, aunque el poder lo detentaba su Hermano Raúl Castro desde:

El 31 de julio de 2006, el Comandante en Jefe Fidel Castro le confió de manera temporal la presidencia de los Consejos de Estado y de Ministros así como el liderazgo del Comité Central del Partido Comunista. Posteriormente, el 24 de febrero de 2008 fue electo Presidente de los Consejos de Estado y de Ministros de Cuba (Raúl Castro, 2017).

No bastaba la desaparición biológica de Fidel, sino que las agudizaciones de las contradicciones económicas políticas y sociales obligan a Cuba a abrirse al capitalismo: "cuál socialismo; en Cuba nunca ha existido, lo único que hay son dictadores, como en Dominicana y en Haitî". 


\section{LOS ALMENDRONES}

Caminar por las calles de La Habana es formidable, es seguro, pero si se desea recorrer el malecón es necesario tomar un taxi; esto es sencillo, se pueden utilizar los autos del Estado o tomar un almendrón, que son más baratos. Estos son los autos viejos que circulaban en Cuba hasta antes de la caída del presidente Fulgencio Batista, en 1959, y que actualmente están reparados, de manera artesanal, por sus propietarios; "quiere un auto particular señor", son las frases que se escuchan por quienes enganchan a las personas para que contraten los servicios de los almendrones.

El testimonio de un taxista de almendrón, modelo 1955, nos menciona en la entrevista que tiene mujer e hija y que gana, aproximadamente, 80 dólares al mes, porque el carro no es de él, lo alquila, "pero un domingo he llegado a sacar hasta $200 \mathrm{CUC}$, y libres ya de la renta". No le interesa salirse de Cuba pero sí lo haría de paseo, y "me gustaría visitar Estados Unidos, allá tengo muchos parientes". El entrevistado es joven, de 35 años, ingeniero civil, pero no ejerce su profesión porque el salario es muy bajo; "yo saco más y no necesito ni mi cartilla de abastecimiento, esa se la dejo a gente que la necesita más que yo". Al hacerle la pregunta relacionada con la revolución y la vida en el socialismo contestó: "no, yo no sé de política, aunque hay mucho ruido ya con el régimen".

En la entrevista realizada a Luis y su acompañante, que tripulan un almendrón, el más viejo tiene 60 años y el joven 36, quien maneja, el primero habla, el segundo calla, "antes de la revolución mi padre tenía este carro, y como le gustó la revolución siguió conservándolo cuando terminó". Al joven le gustaría ir a otro país pero es difícil que le den una visa, está ahorrando para salirse de Cuba y no regresar. "Antes no se podía tener un carro particular ni subir turistas porque te multaban y podían quitarte el carro; ahora pagamos impuestos y puedes hacer negocio". Ahora la vida en Cuba es mejor que antes, "se vive mejor".

Edel, en su testimonio, menciona que con la revolución del socialismo le fue bien a sus padres, pero después la cosa se puso muy difícil. En un principio tuvieron casa y alimentos y ahora ya no es posible vivir bien; si no fuera porque un familiar que trabaja en el ejército le alquila el carro, aunque se queja de lo caro de las descomposturas y la falta de refacciones para ese modelo, un Chevrolet 57: "si se quiebra el carro es muy caro arreglarlo en Cuba", de allí el cuidado que tiene, aunque con las carreteras es difícil no 
caer en hoyos o pisar las latas en la calle, y siempre se les pide a los pasajeros "que no azoten las puertas".

Los ochenta han sido tiempos difíciles; es necesario que "[Cuba] se abra más al capitalismo, el socialismo es solo ya de nombre". Una gran cantidad de jóvenes se han ido de la isla por los bajos salarios en las empresas del gobierno; por ello, considera que es mejor que se abran a los negocios particulares, que sean cuentapropistas; además, está de acuerdo con ello, aunque también enuncia que habrá más clases sociales que ahora, pero "ya nada es parejo en este socialismo". Mientras hacíamos el recorrido dijo: "miren, cuándo iba a ocurrir esto en Cuba" al pasar por el Cabaret de las Vegas, un lugar de show de travestis, y contó que lo que ocurre en el capitalismo ya está sucediendo en la isla con el cambio de los valores; antes "los pajaritos se reunían en un café por el lado del Hotel Nacional y después en el malecón, parecía un avispero, y ahora mire hasta espectáculos. A dónde vamos a llegar". Lo que se gana con un almendrón por día, si se trabaja duro, "yo salgo desde las 6 de la mañana, vengo desde La Víbora y me voy a las tres de la tarde, con mi familia, y saco entre treinta y ochenta CUC, eso sí, como te digo, trabajando muy duro". Menciona las viviendas, las casas que están sosteniéndose y que resisten a la gravedad para no caerse y sepultar a los moradores; "Cuba llora, pero ustedes como turistas no se dan cuenta", cada vez que existe amenaza de ciclón la gente no duerme, siempre espera que termine y que termine bien, que no les deshaga su vivienda, porque los materiales para su reparación son demasiado caros (o no existen).

\section{LO PARECIDO A UNA ENTREVISTA A PROFUNDIDAD}

Fue una entrevista abierta y libre sin necesidad de ocultar ni suavizar las preguntas. La fuente, una mujer de 34 años, casada con un hombre de nacionalidad francesa a quien conoció por internet. Fueron novios durante cuatro años. Ella tiene trabajo en el gobierno, en donde controla los taxis del Estado, domina el inglés, el francés, el italiano y el español, tiene conocimiento del mundo exterior, ha viajado a Francia, República Dominicana y México.

Originalmente, estudió para ser profesora de educación primaria, pero se dio cuenta de que el salario era demasiado bajo y que con ello apenas lograría sobrevivir, o andaría vendiendo maní como muchos profesores, o pensando en hacer costuras en casa. Menciona que el salario mínimo en la actualidad es de $10 \mathrm{cuc}$, que no alcanza para complementar la libreta de abastecimiento, lo que coincide con las cifras que publica la Comisión Eco- 
nómica para América Latina y el Caribe (Cepal), "la isla cerrará 2016 con un salario mínimo de 8,97 dólares al mes y un sueldo medio que "podría ser mayor' a los 27,40 dólares mensuales que se anotaron en 2015" ("Cepal: Cuba cerrará 2016 con un salario mínimo de $\$ 8,97$ dólares al mes", 2016); por esta razón, siempre tuvo la meta de que debería trabajar en otra cosa. Visualizó el sector de turismo, pero para ello se puso a estudiar idiomas porque allí, "como los médicos, debes estar muy bien preparada". Fue tal su suerte que al estudiar francés conoció a quien hoy es su marido.

Las personas en Cuba se sienten muy dolidas con el régimen socialista, principalmente porque están acostumbradas a no trabajar y a que todo se los subsidie el Estado; como el salario mínimo es poco y todo ha subido de precio en Cuba no pueden comprar nada, entonces, para qué trabajar. Esta actitud tiene como consecuencia que la productividad del país sea baja, el mismo escenario que se presentó en URSS:

Eric Hobsbawm da su voto al criterio de que el hombre soviético estaba cómodo en el sistema que le propiciaba una subsistencia garantizada y una amplia seguridad social (al nivel modesto, pero real) una sociedad igualitaria tanto social como económicamente y, por lo menos, una de las aspiraciones tradicionales del socialismo, el derecho a la pereza (Dacal y Brown, 2005, p. 37).

Lo mejor es salir a la calle y encontrarse a un turista que invite a una cerveza o entregue fácilmente una propina por información; pero ahora, que fallan los víveres, ahora sí la gente habla y critica al sistema: "yo lo he hecho siempre y no tengo miedo", esto ya tiene que cambiar, el Estado ya no puede sostener a la población.

Cuba está muy bien en cuestiones de salud, con buenos y suficientes médicos y enfermeras; además de un gran desarrollo de la medicina, reconocida a nivel mundial. Pero las carencias terminan con todo este auge de la medicina al no tener camas suficientes en los hospitales, ni medicamentos, ni instrumental; "hay ciencia pero no tecnología". Además, en los hospitales atienden de manera preferencial; si conoces a alguien consigues cita y hasta medicinas, o hasta una cama, lo que deja claro que en la atención hospitalaria está presente el cohecho, "cómo no, si todos los empleados ya sean médicos, asistentes o manuales ganan lo mismo".

En relación con la educación, reconoce que es muy importante para el país, y que desde la revolución se han implementado medidas para reducir 
el analfabetismo de la población; además, "toda la educación es gratuita", lo que permite que se tenga una población muy ilustrada. Lamentablemente, al salir al campo laboral no hay trabajo, además del bajo salario, por lo que se puede encontrar a profesionales haciendo labores de taxista, "tengo varios choferes que son ingenieros nucleares, civiles, licenciados". La educación de Cuba es reconocida a nivel internacional, pero ya muestra signos de debilidad entre los colegiados académicos; todo el mundo está pensando en hacer otra cosa para sobrevivir, incluyendo a los académicos, principalmente los que están en edad de jubilación. Queda entonces el interrogante: “¿Que harán?”.

"Mira, los cubanos somos fidelistas, pero ya sin él se está terminando la esperanza". El pueblo ha aguantado porque los que hicieron la revolución siempre la apoyaron, aun cuando todo era difícil, pero esos personajes ya están viejos, quedan muy pocos: "mi padre fue militar y aún cree que el Estado está bien, cree que vive de su pensión de 500 pesos cubanos, vive en una burbuja, no le hemos dicho ni de la muerte de Fidel porque se nos muere". A la revolución ya le salieron canas, si hacemos alusión a la canción, postal de La Habana, de Joaquín Sabina; el envejecimiento de las personas que hicieron la revolución y de los sectores sociales convencidos de los logros de la revolución socialista están cambiando: "ya tus hijos y nietos se fueron de la isla, los padres y abuelos se quedaron, Cuba es un país de gente vieja, que tendrá que quedarse aquí. En cuanto muera mi padre, me voy también".

El entrevistado continúa hablando sobre la seguridad en Cuba: siempre ha sido buena, sin embargo los policías se corrompen cada vez más, y esto debido a los bajos salarios y la pérdida de la esperanza para salir adelante; son "proxenetas", se la pasan revisando la calle, buscando y apoyando a las jineteras que se confunden con las personas que llegan al portal de los hoteles, se ponen a beber algo de lata o botella, cerveza, jugo o agua que les "durará una eternidad, pero es la condición para estar sentados". Al parecer los guardias, policías y empleados las conocen, siempre van acompañadas de alguien para que no sea evidente qué buscan: "algún turista con deseos de sexo con alguna mulata negra o blanca, o simplemente para conversar. Es una gran empresa que genera dinero; por ejemplo, para que te suban una jinetera a la habitación del turista es necesario pagar de manera sectaria 45 CuC a los guardias o empleados, ellos te la hacen llegar, camuflajeándola como otra empleada más. Luego viene el reparto de lo ganado". El servicio de las jineteras se convierte en gran negocio, todos ganan, los guardias de los hoteles por permitir que suban a los cuartos de los huéspedes en los hote- 
les, el policía o custodio del barrio, el dependiente del bar y el mesero; todos se encargan de conseguir a pedido lo que desee el cliente, hasta buscarles una silla o mesa para que se sienten entre los clientes turistas; las cosas cambian y demasiado rápido, la corrupción está ganando terreno: "si en este restaurante del Estado al encargado le gustan las ventanas, las cambia o se lleva los vidrios, al fin, para cuando vayan a revisar ya ni se acuerdan cómo estaba el restaurante". La propiedad del Estado nadie la cuida: las guaguas, los establecimientos comerciales, los hospitales son medios para el saqueo y el robo, no queda otra para los trabajadores, tienen que comer.

Con relación a los problemas de género, de manera simplista menciona que "las mujeres le pegan a los hombres y viceversa, en eso sí funciona el socialismo", pero se pone triste cuando habla de las diferencias entre el campo y la ciudad, que son abismales, "ellos viven de la tierra, chozas con piso de terrado, pozo, cultivan lo que se comen o se mueren". Es una entrevista larga, amena e interesante que terminó con una frase, que integró los otros comentarios que se hicieron de manera más emergente e incidental: "El socialismo se acaba, junto con la esperanza".

\section{A MODO DE CONCLUSIONES}

Las dificultades del embargo comercial, más tarde convertido en un bloqueo económico por parte de Estados Unidos, ha originado la carencia de artículos de primera necesidad, lo que lleva a la sociedad cubana a una pobreza extrema.

La estoicidad y el orgullo de la población han sido el factor y la cohesión social ante las condiciones adversas, que están presentes desde el inicio de la década de los años sesenta a la fecha.

La apertura a la economía de mercado se presenta de manera lenta, precisamente porque se desconoce el camino a seguir en la vía del capitalismo; además del pensamiento y de la burocracia en que se ha caído como resultado del estado socialista, proveedor de la reproducción de la vida económica, política, social y cultural.

La República Socialista de Cuba se está quedando sin su fuerza de trabajo y la energía innovadora de los jóvenes, quienes, ante la falta de oportunidades, deciden salir a otros países, principalmente a los Estados Unidos de Norteamérica.

Después de la muerte del general Fidel Castro, ocurrida el 25 de noviembre de 2016, la sociedad cubana empezó a perder la esperanza en el 
modo de producción socialista. Uno de los argumentos es que la sociedad cubana era fidelista.

Está presente una apertura en relación con los medios de comunicación, como el caso de la intercomunicación por redes (internet) a través de wifi, lo que le permite a la comunidad cubana entender otras formas de vida distintas al socialismo, aunque siguen en manos del Estado y con la censura siempre presente.

La libreta de abastecimiento, de la que depende una gran cantidad de la población, se reduce cada vez más y los artículos, para su complemento, son difíciles de alcanzar debido a los salarios mínimos del orden de 10 CUC, y del salario medio o profesional de 27 cuc mensuales.

Los intercambios, o el mínimo comercio, que en inicios de la revolución estaban prohibidos, y se hacían de manera clandestina, ahora son actividades abiertas y legalizadas por el Estado, quien cobra los impuestos a quienes se dedican a ello.

El desmoronamiento de URSS, en 1989, ha sido el factor clave para que la economía socialista haya sido deprimida y, por lo tanto, que el pueblo tenga que adoptar medidas cada vez más austeras y sufridas.

La burocracia, el cohecho, la deshumanización, la falta de productividad están llevando al régimen socialista a cambios, con el fin de abatir estas problemáticas.

Se pensó, en algún momento, que el bloqueo comercial desmedido podría negociarse a finales de la era de Barack Obama, con la visita a la isla el 20 de marzo de 2016 ("Barack Obama llega a Cuba en una visita histórica", 2016). Las puertas se dejaron abiertas para que se continuar con esa política, con el siguiente presidente demócrata, Hillary Clinton, pero la esperanza se terminó con la llegada del candidato republicano Donald Trump y las amenazas de endurecimiento de la política al pueblo cubano.

\section{REFERENCIAS}

Barack Obama llega a Cuba en una visita histórica (2016). BBC Mundo. Recuperado de http://www.jornada.unam.mx/ultimas/2016/03/20/obama-llega-a-cuba-historica-visita-a-la-isla-391.html

Cepal: Cuba cerrará 2016 con un salario mínimo de $\$ 8,97$ dólares al mes (2016). Radio Televisión Martí. Recuperado de https://www.martinoticias.com/a/cuba-incapaz-satisfacer-demanda-turistica/135562.html 
Collazo J. (2001). Fidel Castro Ruz y la Cuba Revolucionaria: un deterioro simultáneo. Contribuciones desde Coatepec, 1(1), 106-139.

"Comes y te vas", la anécdota entre Vicente Fox con Fidel Castro (2016). CNN. Recuperado de http://expansion.mx/mundo/2016/11/26/comes-y-te-vas-la-anecdota-entre-vicente-fox-con-fidel-castro

Dacal, A. (2005). Rusia. Del socialismo real al capitalismo real. La Habana: Editorial de Ciencias Sociales.

El Muro de Berlín. Esta es la historia del símbolo de la Guerra Fría a 27 años de su caída (2016). Perú21. Recuperado de http://peru21.pe/mundo/26-anos-caida-muro-berlin-2231609

Gámez, N. (2016). El éxodo inacabable: ¿Cuántos cubanos han emigrado en los últimos 20 años? El Nuevo Herald. Recuperado de http://www. elnuevoherald.com/noticias/mundo/america-latina/cuba-es/article99869227. html

La crisis de los misiles en Cuba (s. f.). Historiasiglo20.org. Recuperado de http://www.historiasiglo20.org/GLOS/cuba1962.htm

Pérez, F. (2013). Después del derrumbe de los países de la cortina de hierro: la historia hoy. Espacio Abierto, 22(1), 99-109.

Raúl Castro (2017). Recuperado de https://www.ecured.cu/Raúl_Castro

Ruíz-Healy, E. (2015). De 1967 - El revolucionario argentino Ernesto "Che" Guevara es asesinado en Bolivia. Ruiz Healy TIMES. Recuperado de https://mx.tuhistory.com/hoy-en-la-historia/el-revolucionario-argentino-ernesto-che-guevara-es-asesinado-en-bolivia

Yepe, M. (2013). ¿Por qué el bloqueo a Cuba? Diario Granma. Recuperado de http://www.granma.cu/granmad/2013/11/05/cubamundo/artic01. html 